\title{
IHTC15-
}

\section{SUPERHYDROPHOBICITY OR ICEPHOBICITY FOR AN EFFECTIVE ICING MITIGATION STRATEGY?}

\author{
C. Antonini ${ }^{1,2}$, A. Amirfazli ${ }^{3}$, M. Marengo ${ }^{1,4^{*}}$ \\ ${ }^{1}$ Department of Engineering, University of Bergamo, Viale Marconi 5, 24044 Dalmine (BG), Italy. \\ ${ }^{2}$ Laboratory of Thermodynamics in Emerging Technologies, Department of Mechanical and Process \\ Engineering, ETH Zurich, Sonneggstrasse 3, 8092 Zurich, Switzerland. \\ ${ }^{3}$ Department of Mechanical Engineering, York University, Toronto, ON, M3J 1P3, Canada. \\ ${ }^{4}$ School of Computing, Engineering and Mathematics, Cockroft Building, C221, Lewes Road University of \\ Brighton, Brighton, BN2 4GJ, UK
}

\begin{abstract}
There is a growing interest and debate on the role of surface coatings to combat ice accretion on solid surfaces. Most of the studies have focused on "icephobicity", with the aim of either reducing ice adhesion strength or delaying freezing time. Here we present an alternative strategy, which relies on the superhydrophobicity of surfaces as a way to enhance liquid water shedding from a surface prior to freezing. To show in which conditions liquid water drops can rebound and be shed from a solid surface before freezing, drop impact experiments were performed on solid targets characterized by different wettability and thermal properties. The main result is that, when frost formation is avoided on the surfaces (i.e. if surface temperature is above dew point), drop dynamics remains unaffected by solidification effects. In particular, drop rebound can still be achieved down to $-20^{\circ} \mathrm{C}$.
\end{abstract}

KEY WORDS: Two-phase/Multiphase flow, drop impact, superhydrophobicity, icephobicity, icing mitigation, anti-icing coating

\section{INTRODUCTION}

Icing on structures represents a severe risk for human safety and has a significant economic impact on operation costs in many different areas such as aeronautics [1], power systems (e.g. wind turbines [2] and electric power transmission lines [3]), civil construction, and oil platforms to name a few. Atmospheric icing typically occurs when water drops (even in supercooled conditions, i.e. with a temperature below $0^{\circ} \mathrm{C}$ ) hit a surface, stick to it and freeze, causing ice accretion. The negative effects of icing are related to aerodynamic penalties (e.g. on aircraft wings), unpredicted loads and vibrations carrying fatigue damages for structures, and risk of ice shedding, which can lead to safety problems.

To combat icing, several ice protection systems have been designed and implemented, which can be grouped into three categories, in the order of increasing energy requirements (see Table 1). They are: (i) deicing systems, which allow partial ice accretion and cyclical ice removal; (ii) running wet anti-icing systems, by which water is maintained liquid, typically by heating areas where drop impacts, and (iii) evaporative anti-icing systems, which totally prevent ice and liquid water accumulation in the drop collection area and hence also avoid runback ice (i.e. ice formed by liquid water flowing onto unprotected areas). Although generally effective, most of ice protection systems rely on thermal energy and may require heat fluxes up to $25 \mathrm{~kW} / \mathrm{m}^{2}$. As such, new strategies to avoid ice accretion would be desirable, with the goal of increasing

* Corresponding Author: marco.marengo@unibg.it 
safety and reducing energy requirements. In particular, a continuously increasing number of papers [6-23] has focused in the last years on the potentiality of coating strategies as a way to decrease, delay or inhibit ice accretion on a solid surface.

Table 1: Standard ice protection systems

\begin{tabular}{l|l|l}
\hline $\begin{array}{l}\text { Ice protection } \\
\text { systems }\end{array}$ & Operational conditions & $\begin{array}{l}\text { Energy } \\
\text { requirements }\end{array}$ \\
\hline De-icing systems & $\begin{array}{l}\text { Allow partial ice accretion, and } \\
\text { removal is cyclically performed }\end{array}$ & lowest \\
$\begin{array}{l}\text { Running wet } \\
\text { anti-icing systems }\end{array}$ & $\begin{array}{l}\text { Water is maintained liquid, } \\
\text { typically by heating areas in drop } \\
\text { collection areas }\end{array}$ & medium \\
Evaporative \\
anti-icing systems \\
$\begin{array}{l}\text { Avoiding ice accretion in the drop } \\
\text { runback ice (i.e. ice formed by } \\
\text { liquid water flowing onto } \\
\text { unprotected areas) }\end{array}$ & $\begin{array}{l}\text { highest } \\
\left.\text { (up to } 25 \mathrm{~kW} / \mathrm{m}^{2}\right)\end{array}$ \\
\hline
\end{tabular}

\section{Icing mitigation coating strategies}

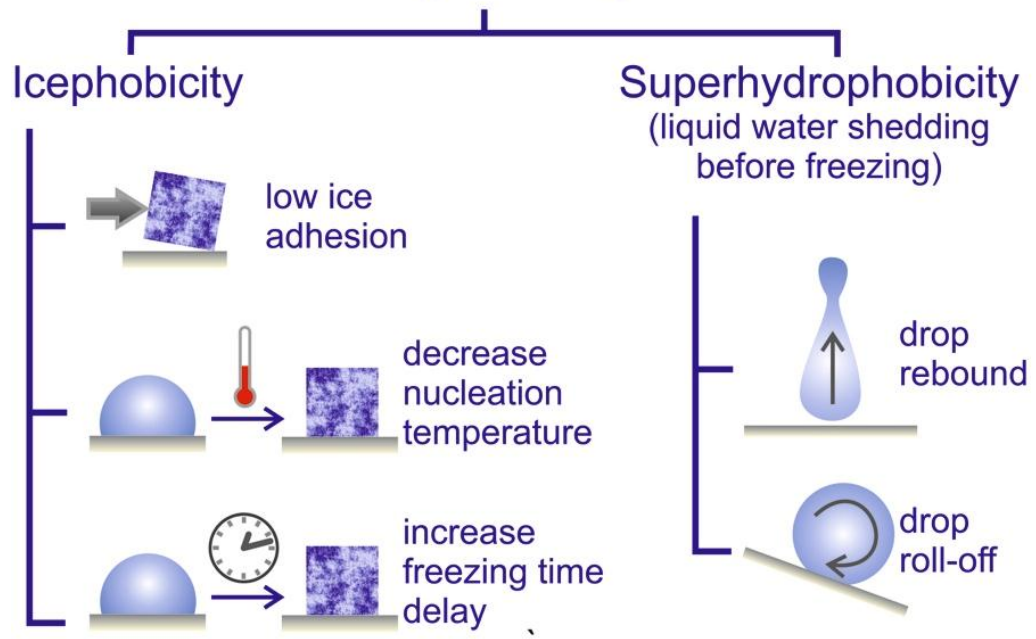

Fig. 1: Schematic of different icing mitigation coating strategies.

Application of coating strategies has opened a debate in the literature about different icing mitigation strategies. Most of studies focus on surface icephobicity, with the goal of either lowering ice adhesion $[8,9,11]$, reducing heterogeneous nucleation temperature [16], or of freezing delay (i.e. the time needed before a supercooled drop freezes on the surface) [7,22], as schematically illustrated in Fig. 1. An alternative strategies is based on exploting surface superhydrophobicity, with the goal enhancing drop shedding by means of drop rebound [28] and drop roll-off [30] (see Fig. 1), before water can freeze on the solid surface. In particular, our focus here was to study the conditions for rebound of liquid water drops in freezing conditions.

Looking at the recent literature, several types of studies, either related to fundamental science of water and ice interaction with a surface [7,13-17,21,23], or to engineering evaluation by means of wind tunnel tests [19], can be found. In most of the cases, results appear contrasting, at least at a first glance. The reason for such discrepancies are related to lack of agreement in the definition of icephobicity, since different mechanisms were investigated (see Fig. 1), and due to the wide variety of test methods and environmental 
conditions: e.g. in ice adhesion tests, ice can be formed on the surface either by accreting ice by accumulation of impacting water drops [6] or forming an ice block by freezing liquid water poured onto the substrate [11,14]; for drop tests, example of tests are solidification of either sessile liquid drops [7,23], flowing liquid water [8], impacting water drops [13,14,17], or drop exposed to shear flow [21]. Since ice nucleation and accretion is generally affected by a variety of factors [23], such as solid surface temperature and morphology, ambient conditions (temperature, humidity), outcome of tests can be dramatically affected, and so the evaluation of surface ability to contrast icing.

In our previous study [19], we presented results from icing wind tunnel tests, where it was shown that the heat load of a thermal anti-icing system could be reduced up to $80 \%$ thanks to the application of a superhydrophobic coating, compared to a reference aluminum surface. In the present paper, we focus on the fundamental physics od drop impact in icing conditions: the aim is to understand the effect of surface wettability, and the effect of environmental conditions (e.g. air humidity) for water drop impact onto surfaces cooled to sub-freezing temperatures, to clarify the potential of superhydrophobic coatings as an icing mitigation strategy.

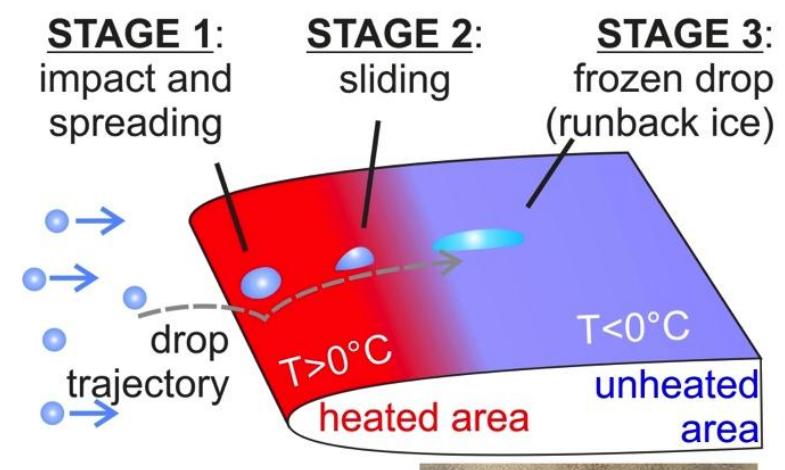

\section{Hydrophilic wing}

(a)
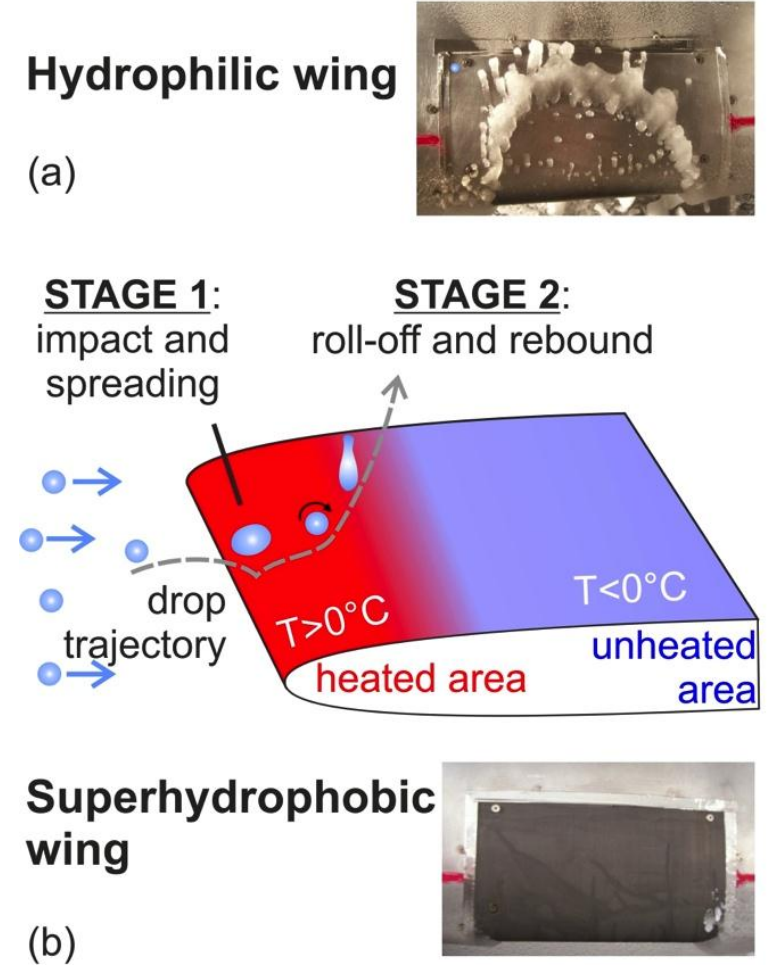

Fig. 2: Schematic of ice accretion on a wing: a) hydrophilic wing; b) superhydrophobic wing. Inset pictures wings top view, showing runback ice accretion on a hydrophilic wing and an ice-free superhydrophobic wing in the same environmental conditions (see text and [19] for details). 


\section{METHODS AND MATERIALS}

Drop impact tests were performed in a specifically designed test rig, where ambient humidity was controlled by injection of dry compressed air at room temperature, and thus control the formation of condensate or frost on the cold surface during tests. The minimum dew temperature that could be reached in the test section was $-20^{\circ} \mathrm{C}$ (corresponding to a relative humidity $\varphi \approx 4 \%$ at $25^{\circ} \mathrm{C}$; absolute humidity of $\sim 0.9 \mathrm{~g} / \mathrm{m}^{3}$ ). The drop was generated at the needle tip, from a reservoir at a constant temperature of $0^{\circ} \mathrm{C}$ (water-ice mixture). The temperature of the target surface, where drops impact, was controlled using a specifically designed cooling system, consisting of two Peltier cells and a liquid cooling heat exchanger. Surface temperature was monitored using two K-type thermocouples. The surface temperature was homogeneous, within $\pm 1^{\circ} \mathrm{C}$. The drop impact was recorded from side by a high-speed camera (PCO camera 1200h).

Drop impact tests were repeated on six different samples, characterized by different wetting and thermal properties: glass, PMMA, Teflon and SHS-Teflon, copper and bare aluminum. Glass samples were ordinary microscope slides. For PMMA, Teflon and SHS-Teflon surfaces, aluminum served as substrate on which various coatings were applied. Details on surface preparation can be found in the Supplementary Material. Table 2 reports measurements of surface wettability (advancing, $\theta_{\mathrm{A}}$, and receding, $\theta_{\mathrm{R}}$, contact angles, and contact angle hysteresis, $\Delta \theta$, obtained by means of sessile drop method), surface roughness and sample thermal effusivity, $\varepsilon=\sqrt{\rho k c_{p}}$, where $\rho$ is density, k thermal conductivity and $\mathrm{c}_{\mathrm{p}}$ specific heat capacity. Under the hypothesis of perfect contact between interfaces and a semi-infinite solid medium, surface thermal effusivity is used to estimate the contact temperature, $\mathrm{T}_{\mathrm{C}}$, i.e. the temperature at the interface between drop and sample upon impact, as:

$$
T_{C}=\frac{\varepsilon_{D} T_{D}+\varepsilon_{S} T_{S}}{\varepsilon_{D}+\varepsilon_{S}}
$$

where subscript $D$ and $S$ refer to drop and sample, respectively.

Drop diameter, $D_{0}$, was kept constant at $2.80 \pm 0.05 \mathrm{~mm}$. The needle was placed at three different heights, to obtain three different impact speeds, $V$, equal to $0.7,1.3$ and $3.4 \mathrm{~m} / \mathrm{s}$, which correspond to Weber numbers, $W e$, of 40, 130 and 450, respectively $\left(W e=\rho V^{2} D_{0} / \sigma\right.$, where $\rho$ and $\sigma$ are water density and surface tension, respectively). These values were chosen because they correspond to moderate, intermediate and high We impact regimes, according to our previous study [28]. Surface temperature was decreased by $5^{\circ} \mathrm{C}$ steps from 5 to $-30^{\circ} \mathrm{C}$. Drop impact could be performed down to $-20^{\circ} \mathrm{C}$ without frost accretion on the surface. Impacting drop temperature was at $0^{\circ} \mathrm{C}$.

Table 2: Characteristics of surfaces used for drop impact tests: advancing, $\theta_{A}$, and receding, $\theta_{R}$, contact angles, contact angle hysteresis, $\Delta \theta=\theta_{A}-\theta_{R}$, surface mean roughness, $R_{a}$, rms roughness, $R_{q}$, and material effusivity. Standard deviation for contact angles is $\pm 2^{\circ}$.

\begin{tabular}{l|c|c|c|c|c|c}
\hline Surface & $\theta_{A}\left[{ }^{\circ}\right]$ & $\theta_{R}\left[{ }^{\circ}\right]$ & $\Delta \theta\left[{ }^{\circ}\right]$ & $R_{a}[\mu \mathbf{m}]$ & $R_{q}[\boldsymbol{\mu m}]$ & $\varepsilon\left[\mathbf{m}^{2} / \mathbf{s}\right]$ \\
\hline Glass & 46 & $<5$ & $\sim 40$ & $0.04 \pm 0.01$ & $0.05 \pm 0.01$ & 1516 \\
PMMA & 88 & 39 & 49 & $0.50 \pm 0.10$ & $0.75 \pm 0.15$ & - \\
Teflon & 123 & 100 & 23 & $0.17 \pm 0.04$ & $0.22 \pm 0.07$ & - \\
SHS-Teflon & 162 & 154 & 8 & $2.70 \pm 0.5$ & $3.40 \pm 0.5$ & - \\
Copper & 92 & 48 & 44 & $0.05 \pm 0.02$ & $0.07 \pm 0.02$ & 37063 \\
Aluminum & 79 & $<10$ & $\sim 70$ & $0.05 \pm 0.02$ & $0.07 \pm 0.02$ & 20507 \\
\hline
\end{tabular}




\section{RESULTS AND DISCUSSION}

Fig. 3 illustrates image sequence of water drop impacting on PMMA, as representative for hydrophilic surfaces, in different conditions: unfrosted surface at temperature of $-10^{\circ} \mathrm{C},-15^{\circ} \mathrm{C}$, and frosted surface at $20^{\circ} \mathrm{C}$. Drop impact speed is $3.4 \mathrm{~m} / \mathrm{s}$ (corresponding to $\mathrm{We}=450$ ). Image sequences in Fig. $3 \mathrm{a}$ and $\mathrm{b}$ (corresponding to the unfrosted surface) show that surface temperature has no effect on drop impact dynamics, neither during spreading nor during recoiling phase. The maximum diameter and spreading is the same for both cases, and also recoiling occurs. No solidification can be observed in the image sequence, not even close to the drop-surface contact area. The impact dynamics changes when frost is present on the sample surfaces (e.g. due to increased ambient humidity, so that surface temperature is lower than dew point). Although no differences can be observed during the spreading phase, once the drop has reached its maximum contact diameter, a pinning of the contact line occurred, drop diameter remained constant and no drop recoil was observed. Even if small layer of frost was present on the surface, barely visible by naked ice, the effect on drop evolution was dramatic, causing a pinning of the contact line.

An important phenomenon that was observed is supercooling. When no frost was present on the surface, it took few seconds before solidification occurs, likely due to supercooling, i.e. the water was cooled down below the freezing point. Solidification of the liquid drop, sitting on the surface after impact, was easily activated by a small perturbation, e.g., by touching the drop: this indicates that the drop was in a metastable system and started freezing once the system was perturbed. After a first stage of solidification, when ice nucleation takes place (the liquid drops become milky, due to presence of a water-ice mixture), with a duration in the order of $10-100 \mathrm{~ms}$ (similar to the case of levitating drops not in contact with a surface [27]), a second stage can be observed, where the solidification front propagates from the drop-surface contact area to the drop front. This second phase is several orders of magnitude slower than the first phase, being in the order of $10 \mathrm{~s} \mathrm{[27],} \mathrm{and} \mathrm{is} \mathrm{mainly} \mathrm{controlled} \mathrm{by} \mathrm{heat} \mathrm{transfer} \mathrm{conduction} \mathrm{in} \mathrm{the} \mathrm{substrate} \mathrm{[29].}$

The other tested smooth hydrophilic and hydrophobic surfaces, such as glass, Teflon, copper and aluminum, were tested. High-speed videos (which are not reported here for brevity) confirm that freezing characteristic times are higher than drop dynamics characteristic times and, if no frost is present on the surface, the drop impact outcome is not modified by surface temperature.

$$
T_{S}=-10^{\circ} \mathrm{C} \text { (unfrosted) } \quad T_{S}=-15^{\circ} \mathrm{C} \text { (unfrosted) } \quad T_{S}=-20^{\circ} \mathrm{C} \text { (frosted) }
$$

before impact

$t=0.7 \mathrm{~ms}$

$t=2.1 \mathrm{~ms}$

$t=10.8 \mathrm{~ms}$

$t=24.1 \mathrm{~ms}$

$t=47.3 \mathrm{~ms}$

$t=68.9 \mathrm{~ms}$

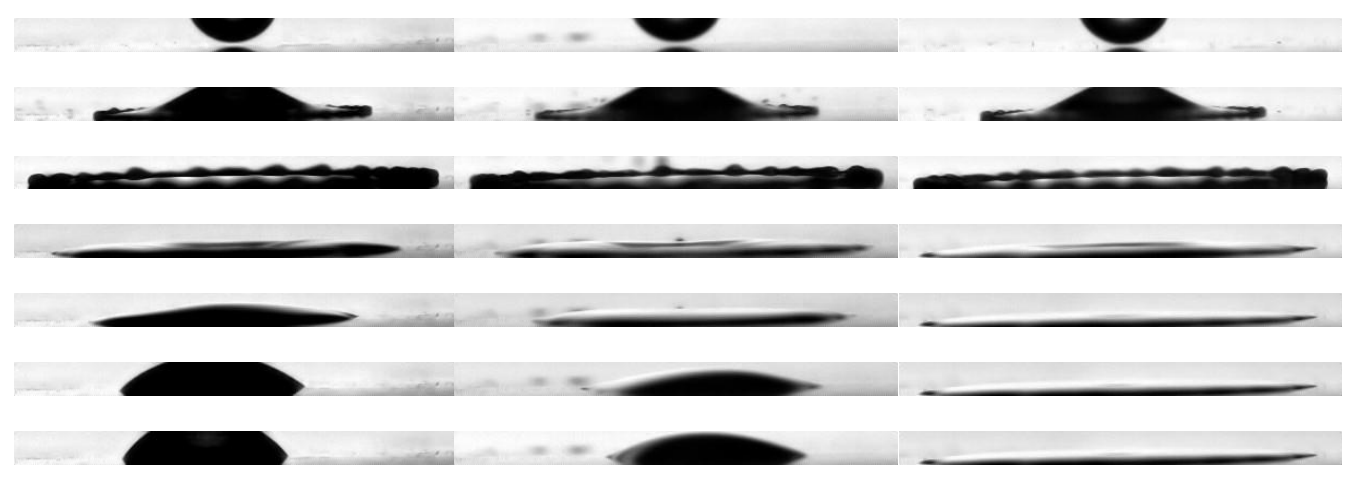

a

b

d

Fig. 3: Water drop impacting on PMMA at different surface temperatures, $T_{S}$. The surface is unfrosted for $T_{S}=-10^{\circ} \mathrm{C}$ and $-15^{\circ} \mathrm{C}$, whereas frost accretes on the surface at $T_{S}=-20^{\circ} \mathrm{C}$. Drop impact conditions are: $D_{0}=2.8 \mathrm{~mm}, V=3.4 \mathrm{~m} / \mathrm{s}(W e=340)$; drop temperature before impact is $T_{D}=0^{\circ} C$.

Fig. 4 illustrates the image sequence of drop impacting on SHS-Teflon in two different conditions for a drop impacting at $3.4 \mathrm{~m} / \mathrm{s}$ : (a) unfrosted surface at $-10^{\circ} \mathrm{C}$, and (c) frosted surface at $-12^{\circ} \mathrm{C}$. As observed for impacts on PMMA, drop dynamics is not affected by surface temperature, if no frost is present on the surface. When surface temperature is at $-10^{\circ} \mathrm{C}$ and no frost is present on the surface (see Fig. 4a), the drop spreads and recoil as in room temperature conditions. No solidification occurs, not even at the drop-surface 
interface, and the drop rebounds from the surface after few ms, with rebound given by $t_{R}=\left(\rho D_{0}^{3} / 8 \sigma\right)^{0.5}$ [33]. We can thus deduce that surface temperature has no effect on drop dynamics for the analyzed superhydrophobic surface and, most importantly, does not affect rebound. Even in the case of higher speed impact, as represented in Figure 4, when secondary drops may be formed due to drop fragmentation or break-up during the initial moments of recoil phase [34], it can be observed that secondary drops maintain a high mobility on the surface, and easy roll away or even rebound. When the video is stopped ( 100ms after impact), such small drops have not frozen yet.

Differently, when SHS-Teflon surface is frosted a considerable effect on drop impact outcome (see Fig. $4 \mathrm{~b}$ ) is visible: after reaching its maximum spreading, recoil phase starts. However, while drop is recoiling ( $\mathrm{t}$ $\sim 8 \mathrm{~ms}$ ), drop contact line remains pinned and only partial rebound occurs, since a consistent part of the drop remains attached to the surface.

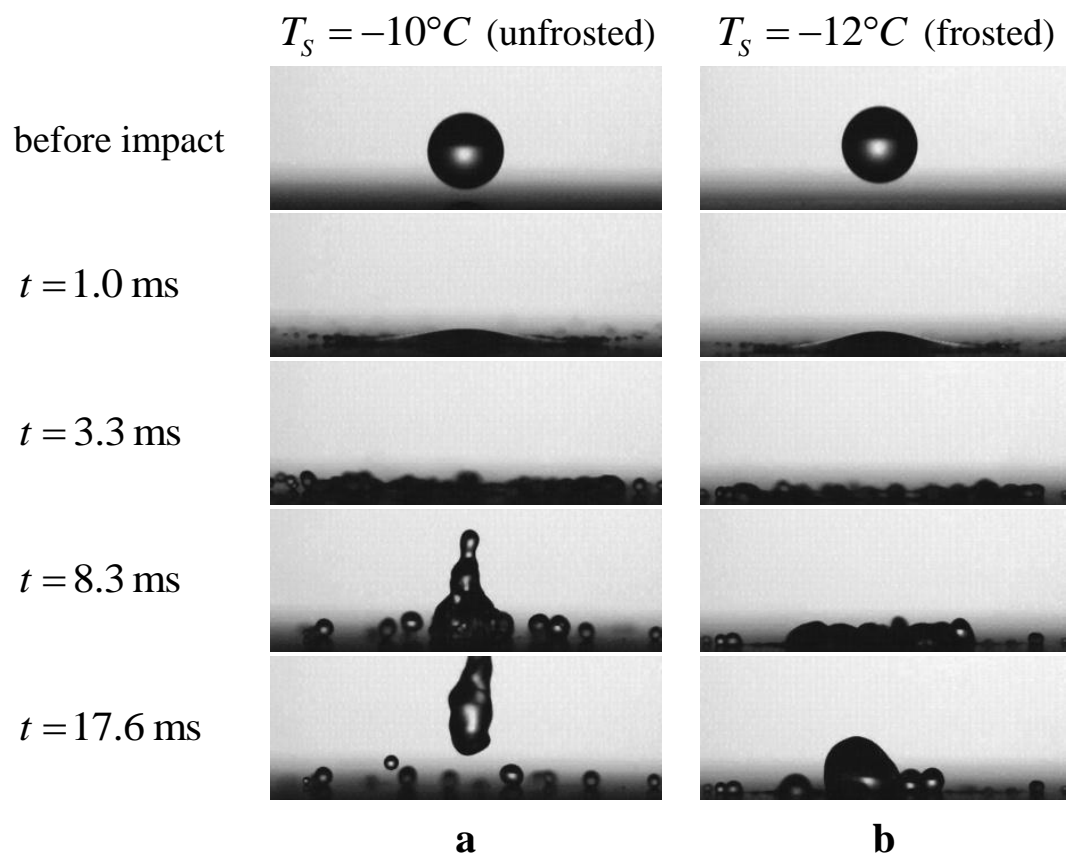

Fig. 4: Water drop impacting on SHS-Teflon at different surface temperatures, $T_{S}$. The surface is unfrosted for case a $\left(T_{S}=-10^{\circ} \mathrm{C}\right)$ and frosted for case $\mathrm{b}\left(T_{S}=-12^{\circ} \mathrm{C}\right)$. Drop impact conditions are: $D_{0}=2.8 \mathrm{~mm}, V=3.4 \mathrm{~m} / \mathrm{s}(W e=340)$; drop temperature before impact is $T_{D}=0^{\circ} \mathrm{C}$.

This means that even on superhydrophobic surfaces the presence of frost affects drop dynamics. However, a difference between hydrophilic surface (PMMA) and SHS-Teflon was found. When frost is present on the surface, drop on PMMA reaches its maximum spreading and does not recoil, i.e. drop contact diameter remains at its maximum value. On a SHS surface, recoil is not completely inhibited; nonetheless, recoil is not complete and drop only partially rebounds from the surface. There might be different reasons for such behavior. In the case of SHS-surfaces, heat transfer between surface and drop is likely reduced by air pockets, which act as insulating layer and retard the solidification of the liquid layer at the drop-surface interface. Second, frost formation on surfaces with different wettability may have a different structure: isolated frost structures, with a snowflake-like shape, were observed on the SHS, whereas on PMMA and in general on hydrophilic surfaces frost was more homogeneous and compact. It is possible that different shape and eventually distribution of nucleation sites may affect drop solidification and thus drop dynamics.

\section{CONCLUSIONS}

To conclude, in the present paper we addressed an alternative coating strategy to combat ice accretion, called "icing mitigation". Instead of focusing on icephobicity, we show how to make use of superhydrophobicity to allow liquid water removal before impact water drops can freeze on a solid surface. Indeed, drop impact experiments showed that drop spreading and recoiling are not affected by solidification 
effects even when surface temperature is below $0^{\circ} \mathrm{C}$ (tested down to $-20^{\circ} \mathrm{C}$ ), if frost is not present on the surface, irrespective of surface effusivity and wettability. For a superhydrophobic surface, this means that rebound will still occur in a no-frost condition. From an application perspective, we can conclude that a superhydrophobic surface can be effective when used in combination with a heating system, that keeps the surface at a temperature above the dew point or, even better, above $0^{\circ} \mathrm{C}$, to avoid presence of ice crystal, which may act as nucleation sites. As such, application of superhydrophobic surfaces can allow a substantial reduction of energy requirements of present thermo-based anti-icing systems: instead of evaporating impacting water drops, drop removal is promoted after impact thanks to water-repellant surfaces.

\section{Acknowledgements}

$\mathrm{CA}$ and $\mathrm{MM}$ acknowledge funding from Regione Lombardia through the grant "Strumenti innovativi per il progetto di sistemi antighiaccio per l'aeronautica" and from AleniaAermacchi. CA acknowledges funding by a Marie Curie Intra-European Fellowship within the 7th European Community Framework Program. The support of David Barona (University of Alberta) in surface fabrication and Mauro Scarpellini (University of Bergamo) for drop impact tests is also acknowledged.

\section{References}

1. R. W. Gent, N. P. Dart, and J. T. Cansdale, 2000, Aircraft Icing, Phil Trans R Soc London A, 358, 2873-2911.

2. N. Dalili, A. Edrisy, and R. Carriveau, 2009, A review of surface engineering issues critical to wind turbine performance, Renew Sust Energ Rev, 13 (2), 428-438.

3. M. Farzaneh, 2008. Atmospheric Icing of Power Networks, ed. Springer.

4. B. L. Messinger, 1953, Equilibrium temperature of an unheated icing surface as a function of airspeed, $\mathbf{J}$ Aeronaut Sci, 20, 29-42,

5. R. J. Kind, M. G. Potapczuk, A. Feo, C. Golia, and A.D. Shah, 1998, Experimental and computational simulation of in-flight icing phenomena, Prog Aerosp Sci, 34, 257-345.

6. S. A. Kulinich, and M. Farzaneh, 2009, Ice adhesion on super-hydrophobic surfaces, Appl Surf Sci, 255, 8153-8157.

7. P. Tourkine, M. Le Merrer, and D. Quéré, 2009, Delayed Freezing in water repellent materials, Langmuir, 25, 7214-7216.

8. J. B. Boreyko, and C. P. Collier, 2013, Delayed Frost Growth on Jumping-Drop Superhydrophobic Surfaces, ACS Nano, 7, 1618-1627.

9. J. B. Boreyko, B. R. Srijanto, T. D. Nguyen, C. Vega, M. Fuentes-Cabrera, and C. P. Collier, 2013, Dynamic Defrosting on Nanostructured Superhydrophobic Surfaces, Langmuir, 29, 9516-9524.

10. L. Cao, A.K. Jones, V.K. Sikka, J. Wu, and D. Gao, 2009, Anti-icing superhydrophobic coatings, Langmuir, 25 (21), 12444-12448.

11. A.J. Meuler, J. D. Smith, K. K. Varanasi, J. M. Mabry, G. H. McKinley, and R. E. Cohen, 2010, Relationships between Water Wettability and Ice Adhesion, ACS Appl Mater Interfaces, 2, 3100-3110.

12. A. J. Meuler, G. H. McKinley, and R. E. Cohen, 2010, Exploiting topographical texture to impart icephobicity, ACS Nano, 4 (12), 7048-7052.

13. L. Mishchenko, B. Hatton, V. Bahadur, J.A. Taylor, T. Krupenkin, and J. Aizenberg, 2010, Design of ice-free nanostructured surfaces based on repulsion of impacting water droplets, ACS Nano, 4, 76997707.

14. K. K. Varanasi, T. Deng, J. D. Smith, M. Hsu, and N. Bhate, 2010, Frost formation and ice adhesion on superhydrophobic surfaces, Appl Phys Letters, 97, 234102.

15. S. Jung, M. Dorrestijn, D. Raps, A. Das, C. M. Megaridis, and D. Poulikakos, 2011, Are Superhydrophobic Surfaces Best for Icephobicity?, Langmuir, 27, 3059-3066.

16. T. V. J. Charpentiera, A. Neville, P. Millner, R. W. Hewson, A. Morina, 2013, Development of antiicing materials by chemical tailoring of hydrophobic textured metallic surfaces, J Colloid Interface Sci, 394, 539-544.

17. L. Zheng, Z. Li, S. Bourdo, K. R. Khedir, M. P. Asar, C. C. Ryerson, and A S. Biris, 2011, Exceptional Superhydrophobicity and Low Velocity Impact Icephobicity of Acetone-Functionalized Carbon Nanotube Films, Langmuir, 27, 9936-9943. 
18. V. Bahadur, L. Mishchenko, B. Hatton, J. A. Taylor, J. Aizenberg, and T. Krupenkin, 2011, Predictive Model for Ice Formation on Superhydrophobic Surfaces, Langmuir, 27, 14143-14150.

19. C. Antonini, M. Innocenti, T. Horn, M. Marengo, and A. Amirfazli, 2011, Understanding the Effects of Superhydrophobic Coatings on Energy Reduction in Anti-Icing Systems, Cold Reg Sci Tech, 67, 58-67.

20. S. A. Kulinich, S. Farhadi, K. Nose, and X. W. Du, 2011, Superhydrophobic Surfaces: Are They Really Ice-Repellent?, Langmuir, 27 (1), 25-29.

21. S. Jung, M. K. Tiwari, N. V. Doan, and D. Poulikakos, 2012, Mechanism of supercooled droplet freezing on surfaces, Nat Commun, 3, 615.

22. A. Alizadeh, M. Yamada, R. Li, W. Shang, S. Otta, S. Zhong, L. Ge, A. Dhinojwala, K. R. Conway, V. Bahadur, A. J. Vinciquerra, B. Stephens, and M. L. Blohm, 2012, Dynamics of Ice Nucleation on Water Repellent Surfaces, Langmuir, 28 (6), 3180-3186.

23. G. Fang, Y. Maham, A. Amirfazli, and Understanding the Role of Surface Micro-texture on the Delayed Freezing of Drops on Cold Surfaces, 2011, ASME- ICNMM2011, Jun 19-22, Edmonton, Canada.

24. A.L. Yarin, 2006, Drop Impact Dynamics: Splashing, Spreading, Receding, Bouncing.... Annu Rev Fluid Mech, 38, 159-192.

25. M. Marengo, C. Antonini, I.V. Roisman, and C. Tropea, 2011, Drop collisions with simple and complex surface, Curr Opin Colloid Interface Sci, 16, 292-302.

26. M. Ma, and R. M. Hill, 2006, Superhydrophobic surfaces, Curr Opin Colloid Interface Sci, 11, 193-202.

27. S. Bauerecker, P. Ulbig, V. Buch, L. Vrbka, and P. Jungwirth, 2008, Monitoring Ice Nucleation in Pure and Salty Water via High-Speed Imaging and Computer Simulations, J Phys Chem C, 112, 7631-7636.

28. C. Antonini, A. Amirfazli, M. Marengo, 2012, Drop impact and wettability: from hydrophilic to superhydrophobic surfaces, Phys Fluids 24, 102104, 2012.

29. H. Pruppacher, J. D. Klett, 1998, Microphysics of Clouds and Precipitation, ed. Kluwer Academic Publishers, 976p.

30. A.J.B. Milne, and A. Amirfazli, 2009, Drop shedding by shear flow for hydrophilic to superhydrophobic surfaces, Langmuir 25, 14155-14164.

31. T. Nishino, M. Meguro, K. Nakamae, M. Matsushita, and Y. Ueda, 1999, The Lowest Surface Free Energy Based on -CF3 Alignment, Langmuir, 15, 4321-4323.

32. X. Zhang, F. Shi, J. Niu, Y. Jiang and Z. Wang, 2008, Superhydrophobic surfaces: from structural control to functional application, J Mater Chem, 18, 621-633.

33. D. Richard, C. Clanet, D. Quéré, 2002, Contact time of a bouncing drop, Nature, 417-811.

34. R. Rioboo, C. Tropea, and M. Marengo, Outcomes from a drop impact on solid surfaces, 2001, Atomization Sprays 11, 155-165. 